\title{
Significance of E-Learning Tools in Teaching English
}

\author{
Dr. K Latha \\ Professor of English \\ SV College of Engineering \\ Tirupati, Andhra Pradesh, India \\ lathareddykadiri@gmail.com
}

\begin{abstract}
We are living in a world where technology is omnipresent. Due to the ubiquitous presence of technology the pedagogy of teaching methodology has also undergone a sea-change. The phrase "e-Learning" or "Technology in Education" has become the buzz word in every educational environment. Infusing technology into education is really important as it caters the needs of the contemporary learners. The classroom environment, today, is completely different from the conventional classroom. The traditional methods, which are mainly based on lecturing and rote learning reduce, English language learning to mechanical memorization and miserably fail in developing English language as a skill among the learners. New technologies like Internet, YouTube, Skype, tweeter, blogs, mobile phones, interactive boards and many more have added not only stimulus but also learners' communication and true interactivity within the classroom. Learning is, of course, the main purpose of education. It is the goal of every student and the task of every teacher to increase knowledge and understanding in the classroom. The teachers can engage the learners to become skilled at English Language by using the innovative ELT techniques like English songs, movie clippings, dramatics, advertisements, sports commentaries and many more. This paper stresses on the need to make English language lessons easy and enjoyable through innovative
\end{abstract}


ELT methods. This is done first by giving a brief review about the traditional teaching methods in India and further the focus will be on instilling Information and Communications technologies (ICT) tools in ELT. Thus this study confers the availability of various tools of ICT and their practical uses.

Keywords: ELT, Technology, Techniques, Communication, Tools.

As there is enormous increase in the number of English language learners, educators are seeking effective programs and instructional strategies to serve them. Any path for applied linguistics should provide a comprehensive range of research-based language and cultural education resources and testing tools. Teachers could adapt best curriculum and instructional strategies for students learning English. They must provide a variety of materials and technology to help English language learners in the classroom.

Technology lends itself to exploration. But before technology is used effectively, exploration must be valued as important to both teaching and learning. Teaching - especially in the humanities - should always strive to move beyond the simple divulging of facts and knowledge or even the training of certain skills. Learning is, of course, the main purpose of education. It is the goal of every student and the task of every teacher to increase knowledge and understanding in the classroom. The present paper tries to show general frame and importance of technology applied for teaching of language. Then, the role of technology as well as learning will be explained. It is hoped to come to some conclusions by showing some corrections in the strategies and curriculums of English language teaching programs.

Teachers are being suggested to learn new methods of teaching, while at the same time are facing even greater challenges of rapidly increasing technological changes and greater diversity in the classroom. Need for education is inevitable even if it isn't necessary under law. Life is not static, change is the law of nature and every educational organization 
has to keep pace with changing environment, which is beyond human control. One has to update his knowledge to keep the activities under his direction and suitable guidance. Every educational organization needs to have well teacher and experienced people to perform the activities that have to be done. Teachers in a liberal arts environment have the broad responsibility of serving as guide and mentor on an intellectual journey, opening and broadening curious minds by exposing them to new thoughts and ideas. As with anyone involved in education, student or teacher, a personal growth plan should always be included. One never develops socially, intellectually, or academically, without consistently learning new things and determined to further oneself. This can embrace classes as a part of a continuing education program, receiving regular input from students and consistently attempting to improve their teaching style, or trying new ideas or strategies on regular basis.

With the spread and development of English around the world, English is used as a second language in a country like India and for some people the $1^{\text {st }}$ language. It enjoys a high prestige in the country. At present, the role and status of English in India is higher than ever as evidenced by its position as a key subject of medium of instruction, curriculum. As the number of English learners is increasing different teaching methods have been implemented to test the effectiveness of the teaching process. Use of authentic materials in the form of films, radio, TV has been there for a long time. It is true that these technologies have proved successful in replacing the traditional teaching.

The new era assigns new challenges and duties on the modern teacher. The tradition of English teaching has been drastically changed with the remarkable entry of technology. Technology provides so many options as making teaching interesting and also making teaching more productive in terms of improvements. Technology is utilized for the upliftment of modern styles; it satisfies both visual and auditory senses of the students. With the spread and development of English around the world, English has been learned and used by more 
and more speakers. According to David Graddol 'it is the language at the leading edge of Corresponding author.

As the use of English has increased in popularity so has the need for qualified teachers to instruct students in the language. It is true that there are teachers who use "cutting edge' technology, but the majority of teachers still teach in the traditional manner. None of these traditional manners are bad or damaging the students. In fact, till date they are proving to be useful also. However, there are many more opportunities for students to gain confidence practice and extend themselves, especially for ESL students who learn the language for more than just fun. For them to keep pace with ELT and gain more confidence they have to stride into the world of multimedia technology.

Use of E-Learning Tools in Teaching English

Internet

Internet is not merely a source of authentic material in English but also a source of information in the form of articles, courses, conferences and many more. The teacher can send assignments to the students through e-mails and can also take online exams. Parents can view their children's work online at any time. Students do not miss their lessons as now they can see a web cam version online and get worksheets and notes from electronic online whiteboards. Schools are linked in a network and work on projects together and prepare materials online. Every school has got its own website. Many software are also available on Internet that students can use free of cost. Spelling Bee is one of those an internet resources, which helps the students to spell English words. The teacher can also choose the level of difficulty that s/he wants to train to his/her students. 


\section{Using YouTube}

YouTube videos can be used in an ELT classroom for various aspects of English as to enhance vocabulary, accents, pronunciations, voice modulation and many more. The real advantage of using YouTube in teaching English is that it offers authentic examples of everyday English used by everyday people. The teacher can use it as a tool for improving their Listening and Speaking, Reading and Writing skills. The teacher can select a part of the movie appropriate to the level of the students and s/he can show those movie clippings to the students. For the first time, s/he can mute the volume and ask the students to watch the movie attentively. Later s/he can ask the students to watch the movie once again and this time $\mathrm{s} / \mathrm{he}$ can ask the students to frame the dialogues of the movie clippings simultaneously. This will improve their speaking skills. Another activity to enhance their speaking skills can be: the teacher can show a selected part of the movie to the students and further ask them to narrate the rest of the story of the movie or the climax of the movie. This will add to their creativity as well as their speech. The teacher can also prepare worksheets on the movie clippings in advance and ask the students to complete those worksheets while watching movies. This can prove a good activity to enhance their listening and writing skills. The teacher can also ask the students to write a paragraph related to the movie as: "If I were the hero of the movie. ." Or "What, according to you, should be the title of the movie?" Listening skills can also be enhanced through YouTube as news headlines are available to watch on YouTube. As the news is summarized very quickly (in the first minute for the video below), the teacher can ask students to listen to the news headlines and put those headlines in order (where they will have the headlines on a handout). 
Skype

Using Skype provides unlimited possibilities for the teachers and students to collaborate with each other anywhere in the world. It provides immense opportunities for the students in a foreign language class to connect with classes in other countries to practice their language skills. Through Skype the teachers can provide mentoring or homework help to the learners. The Students can read, present, or perform for other students and also collaborate with other students on writing or research projects. They can also participate in professional development activities within or outside the school district.

Twitter

Twitter, a gift of Technology, is a social networking application that could help in improving students' English to a greater extent. As an online education technology tool, twitter's impact on engaging students in learning concepts is unlimited. The teacher can use a dozen activities for using an online education technology tool to engage students in classroom activities to develop a better understanding of concepts. The teacher can select any genre for the story and begin the activity with a story opener which is tweeted to the students for contribution to the story line. Once all twitter network participants have contributed to the development of the story line, the teacher can analyze their work. This involves editing, story structure, creative writing, and proper use of grammar.

The teacher can ask the students to select a word of the week and tweet it around the network requesting synonyms, homonyms, and antonyms of the word. Once all responses are received, the teacher can check them for accuracy and develop a link of the difficult words for strengthening the vocabulary of the students. The teacher can also conduct Online Debates through Twitter. It can be done with the students of the same classroom or the 
students of the different classrooms on the class twitter network. Examples include "Pen is mightier than sword", impact of fast food restaurants on

health issue, and many more.

Smart-boards

Interactive whiteboards are good replacements for traditional whiteboards or flipcharts as they provide ways to show students everything which can be presented on a computer's desktop (educational software, web sites, and others). SMART boards help teachers use a student-centered approach to teach language arts. Language arts teachers can use SMART Boards to improve reading and comprehension, and teach grammar and writing. With a SMART Board, teachers can combine video, audio, Web browsing and word processing to teach students interactively. The teacher can use smart board to enhance students' language skills in play way method. For e.g. 'Pictogram' (Draw a picture and guess the word) can be played. With younger learners spelling races are very popular. Word games are an excellent way of settling classes and revising vocabulary. S/he can use anagrams or jumbled sentences for the Learners or s/he can also ask the synonyms or antonyms or the lexis or collocation words. The teacher can use different colours when writing. The teacher can also display paragraphs with errors and ask the students to edit the paragraphs or proofread them. To teach writing skills the teacher can also use a story starter and ask the students to write a class story or chain story or peer story. S/he can also write sentences based on photographs as it will teach them the usage and functions of the language. S/he can further use photographs of persons (i.e. characters from book, persons from history) and can ask the students to write in "bubble" about their thoughts. 


\section{Mobile Phones}

The use of mobile phones as a learning tool has a wide variety of applications. The teacher can ask the students to make a photo documentary using the camera function on their mobile phones. The teacher can assign a theme for the documentary to the students. After taking a sufficient number of photos, the students can upload the documentaries prepared by them to websites such as Flicker and type narrative descriptions for each picture to share with their teachers, classmates, family and friends. Instead of taking out a dictionary, the students can simply use their translator, and instead of trawling through books for a piece of literature, they can find the book online books and be directed to a specific word.

\section{Podcasting}

Today, the students are listening to news clips, music, and video clips via the Web. They are no longer watching movies at the theatre or on the TV, they are watching via computers and hand held DVD players. The teacher can reach to these students in one new way i.e. through podcasts. A podcast is a series of digital-media files which are distributed over the Internet using syndication feeds for playback on portable media players and computers. Utilizing podcasts in the classroom is very easy. The teacher can download many free ESL podcasts on the Internet to use in class. S/he can assign a podcast assignment for homework and form a discussion on the topic the next day. The teacher can also assign a music podcast that introduces students to the culture as well as how the language is often used creatively or the news channels through which the student can also learn the use of intonation and stress. 
$\mathrm{B} \log$

Blogging has become increasingly popular, especially in the realm of education as they are a great way to share information and generate discussion. Instead of text books and traditional methods, many educators prefer using these new techniques to help teach students and gain experience with various forms of social media. Setting up a course blog doesn't have to be complicated. Educators can use a free platform such as Blogspot, Wordpress, or Tumblr to host the blog. Nowadays, blogs can also display photos and some people are using them with audio and even video, the teacher should encourage the students to visit blog frequently. S/he should respond to student posts quickly, writing a short comment related to the content S/he should also ask questions about what the learner writes to create stimulus for writing. Writing to the blog could be required, and it may form part of the class assessment. Students should be encouraged to post their writing homework on the blog instead of only giving it to the teacher.

\section{Conclusion}

As English has turned into a universal language, its presence and value in the world has expanded enormously in the past decades. But if language teachers teach as they taught earlier, then the required goals of learning English Language may not be achieved in the present global scenario. In the past, no productive, creative and constructive activity was given to the learners to develop the four language skills. With the changing needs of the hour (time), technology is developing day-by-day. We are living in the 21 st century and it is the age of technological advancement. Thus the recent trend in teaching English is the use of modern technological tools as English language teaching has been affected a lot with the availability of these tools. 


\section{References}

Cox, M.J., Preston, C., \& Cox, K. (1999) What Motivates Teachers to use ICT?. Paper presented at the British Educational Research Association Conference. Brighton. September Desforges, C. (1995)

Higgins, S. and Moseley, D. (2001) Teachers' thinking about ICT and learning: beliefs and outcomes. Teacher Development 5.2, pp 191-210.

Jacob Tharu, 2006. "A second look at English as a window on the world that has changed," Communication Curriculum in Higher Communication: Challenges \& Opportunities.

Jarvis, H. (2005). Technology and change in English Language Teaching. Asia TEFL Journal, 7(4), 213-227.

Rank Tom, Millum Trevor, Warren Chris. Teaching English Using ICT: A Practical Guide for Secondary School Teachers. 